\title{
Assessment of Efficiency and Effectiveness of the Enterprise Economic Security Management System
}

\author{
Khoroshilova O.V.* \\ Plekhanov Russian University of Economics \\ Voronezh Branch, Russia \\ e-mail: oxoroshilova@vfreu.ru
}

Kavyrshina O.A.

Plekhanov Russian University of Economics

Voronezh Branch, Russia

e-mail: okavyrshina@vfreu.ru

Novikova N.E.

Plekhanov Russian University of Economics

Smolensk Branch, Russia

e-mail: ne.novikova@smolreu.ru

\begin{abstract}
The subject of the research is the enterprise economic security management system (EESMS). The aim of the work is the formation of a methodology for assessing the effectiveness and efficiency of EESMS. As a result of the study, the tasks of evaluating the effectiveness and efficiency of EESMS are substantiated and the essence of ESMS is revealed. We systematized the problems of EESMS assessment, substantiated the feasibility of developing a methodology for assessing the effectiveness and efficiency of EESMS based on the Balanced Scorecard concept. We also proposed a methodology for assessing EESMS based on the assessment of an integrated performance indicator and an EESMS performance indicator. In the article, EESMS is considered as a set of interconnected elements, which carries out planning, organization, coordination, motivation, analysis and control of activities to ensure the economic security of this enterprise. The end result of the EESMS functioning is to ensure the security of the economic interests and economic potential of a given business entity from external and internal threats in the short and long term. The immediate results of the EESM are the results of processes aimed at achieving the target level of economic security of the enterprise. It is proposed to consider the effectiveness of EESMS as the degree of achievement of the target level of economic security of the enterprise and the level of implementation of plans for ensuring economic security. EESMS effectiveness assessment is carried out on the basis of comparing the system performance with the level of budget execution for EESMS functioning. The proposed methodology for evaluating the effectiveness and efficiency of EESMS takes into account the final and immediate results, which allow identifying the needs for improving EESMS.
\end{abstract}

Keywords - economic security, management system evaluation, efficiency, effectiveness, enterprise security.

\author{
Bokovaya N.V. \\ Plekhanov Russian University of Economics \\ Voronezh Branch, Russia \\ e-mail: nelli_g_b@mail.ru
}

Dedova E.S.

Plekhanov Russian University of Economics Voronezh Branch, Russia e-mail: ededova@vfreu.ru

Timofeeva E.M.

Plekhanov Russian University of Economics Voronezh Branch, Russia e-mail: etimofeeva@vfreu.ru

\section{INTRODUCTION}

In Russia, the last decade is characterized by introduction of economic security management subsystems in the management systems of medium and large enterprises. Organizations welcome economic security services, technical and software activities of these services receive investments. Moreover, there are modern digital technologies that are introduced to identify threats, local regulations are being developed that regulate activities to ensure the economic security of organizations

The most important condition for the development of the enterprise economic security management system (EESMS) is the assessment of its effectiveness and efficiency. The assessment should be carried out by management with planned frequency and it should be solving the tasks of monitoring goals achievement. At the same time, it should be identifying potential risks of reducing the efficiency of functioning and determining ways of further improvement

The presence of various approaches to the analysis of EESMS, understanding the essence and results of its functioning complicates the evaluation process and reduces the practical value of the conclusions.

The aim of the study is to formulate the methodological provisions for evaluating EESMS, which brings us to the conclusion that the system is effective and efficient.

In this study, it is necessary to systematize the current problems of assessing the economic security management system of Russian enterprises and identify the causes of their occurrence, to determine the types of EESMS functioning results and to propose a methodology for evaluating the effectiveness and efficiency of EESMS, which allows 
monitoring the achievement of functioning goals and objectives and timely identifying improvement needs.

\section{LITERATURE REVIEW}

The economic security of the enterprise is considered as safety of economic interests and economic potential of a given business entity from external and internal threats, which provides conditions for achieving its long-term goals [1].

The economic security of the enterprise as a scientific direction is in the process of formation [2], which requires clarification of the conceptual framework, including determining EESMS nature, efficiency of EESMS, and effectiveness of EESMS.

Economic security management is a set of interrelated processes of planning, organization, motivation and control, ensuring economic security of the enterprise [3, 4].

From the position of a systematic approach, the management of the economic security of an enterprise must be investigated as an open system, which at the same time is a subsystem of the enterprise management system [5].

EESMS is proposed to understand a set of interconnected elements, which carries out planning, organization, coordination, motivation, analysis and control of activities to ensure the economic security of this enterprise.

Based on the definitions given in the dictionary [6], the EESMS performance is considered as "the degree of implementation of the planned activity and achievement of the planned results"; EESMS performance characterizes the relationship between the results achieved by EESMS and the costs of achieving them."

There is currently no generally accepted approach to evaluating EESMS. In the course of the research of scientific works, the following approaches are identified:

- based on an assessment of the level of economic security of the enterprise [7] - the higher the level of economic security, the more efficient the EESMS;

- based on an assessment of the ratio of the amounts of prevented damage and reduction of losses to the costs of the functioning of the system $[8,9]$;

- based on assessment of the speed of the enterprise's response to changes in the external environment [10] the higher the speed of creating an objective analytical assessment of the external market situation, the speed of making managerial decisions to change plans and the speed of implementation of decisions made, the higher the efficiency of EESMS.

Considered approaches differently interpret the results of EESMS functioning. They focus only on certain areas of EESMS assessment and do not allow monitoring goals and timely identifying potential risks of reducing the efficiency of this system.

The first approach to evaluation of EESMS functioning considers increasing or maintaining the level of economic security of the enterprise. The level of economic security of an enterprise characterizes the degree of protection of economic interests and the economic potential of a given business entity from external and internal threats. There are various approaches to assessing the level of economic security of an enterprise. The approach based on a comparison of threshold and actual values of indicators with the subsequent calculation of the integral indicator prevails. Scientific sources propose a different set of indicators to assess the level of economic security. In most cases [7, 11-14], both financial and nonfinancial indicators are used. The question of threshold indicators remains open.

The second approach to evaluation of EESMS functioning considers the prevention and compensation of damage $[8,9]$ caused to the enterprise in connection with the adverse effects of external and internal factors. The higher the monetary value of the prevented and compensated damage and the lower the cost of operating the system, the higher the effectiveness of EESMS. This approach unreasonably narrows the result of the operation of EESMS, focusing only on ensuring the return on this system.

Assessment of response speed to changes in the external environment characterizes the property of EESMS to ensure the adaptability of the enterprise, and not the level of protection of the economic interests and economic potential of the enterprise from external and internal threats. Evaluation of the indicators used by the approach [10] does not allow us to conclude that EESMS is effective and efficient.

The presence of identified problems justifies the need to develop a methodology for evaluating the effectiveness and efficiency of EESMS, clarifying the types of results of its functioning.

\section{Methodology}

The object of the study are Russian enterprises with more than 250 employees, which behold departments or economic security services.

Diagnosis of EESMS assessment problems was carried out using the diagnostic interview method.

The interview was conducted with the heads of enterprises and the heads of services (departments) of economic security in order to obtain answers to research questions:

- Is the problem of evaluating the effectiveness and efficiency of EESMS relevant?

- What local regulatory act governs the EESMS assessment methodology?

- How often do you evaluate the effectiveness and efficiency of EESMS?

- What are the objectives of the EESMS assessment?

- What methodologies and indicators are used to evaluate EESMS?

- What are the challenges of evaluating EESMS?

- Which of the approaches proposed in the scientific literature for evaluating EESMS is most preferable? 


\section{RESULTS}

The heads of enterprises and the heads of services (departments) of economic security of large and medium-sized Russian enterprises indicate the urgency of EESMS assessment. However, they do not clearly distinguish the distinctive characteristics of evaluating the effectiveness and efficiency of these systems. At the enterprises there are no approved EESMS assessment methods, in rare cases, the local regulatory acts determine the composition of financial and non-financial performance indicators. Key findings are based on subjective assessments.

The objectives of the EESMS assessment at Russian enterprises:

- monitoring the achievement of the planned results of the functioning of the EESMS;

- determination of the level of material incentives for employees;
- substantiation of the volume of financing of the economic security service;

- identification of the need for reorganization of the EESMS.

In almost all enterprises, the following indicators are calculated to evaluate the EESMS: costs of ensuring economic security, level of budget execution of the costs of the economic security service, amount of damage prevented, amount of damage detected and compensated. In some cases, we assess the level of economic security of the enterprise. Evaluation is carried out no more than once a quarter.

Leaders do not consider the approaches used to evaluate EESMS to be optimal and point out the insufficient theoretical and methodological development of this area.

The study made it possible to identify and systematize the problems of EESMS assessment in large and medium-sized Russian enterprises (table 1).

\section{TABLE I. EESMS EVALUATION ISSUES}

\begin{tabular}{|c|c|}
\hline Approach & Problems \\
\hline $\begin{array}{l}\text { 1. Based on the assessment of the level of } \\
\text { enterprise' economic security }\end{array}$ & $\begin{array}{l}\text { 1. It is difficult to highlight the contribution of EESS to the dynamics of the level of economic security of the } \\
\text { enterprise. This level was formed at the time of the assessment under the influence of various factors of the internal } \\
\text { and external environment. Thus, the evaluation of the effectiveness of EESM can be unreasonably overestimated } \\
\text { or underestimated. } \\
\text { 2. The insufficient development of the methodology for assessing the level of economic security of the enterprise, } \\
\text { adapted to the goals of evaluating the effectiveness and efficiency of EESM. } \\
\text { 3. Existing methods for assessing the level of economic security of an enterprise do not take into account the costs of } \\
\text { resources allocated to the operation of EESM. }\end{array}$ \\
\hline $\begin{array}{l}\text { 2. Based on the assessment of the ratio of } \\
\text { the amounts of prevented damage and } \\
\text { reduction of losses to costs of system } \\
\text { functioning }\end{array}$ & $\begin{array}{l}\text { 1. It does not take into account the results of EESM aimed at the implementation of measures for the prevention of } \\
\text { economic crimes, offenses and risk management. Efficiently built procedures, algorithms to ensure economic } \\
\text { security and strict adherence to the principle of punishment inevitability reduce internal threats, and, consequently, } \\
\text { the amount of damage and losses prevented. } \\
\text { 2. The insufficient development of the methodology for assessing prevented damage, which is the result of increased } \\
\text { protection of economic interests and the economic potential of the enterprise from external threats. A high level of } \\
\text { subjectivity of the assessment results. } \\
\text { 3. It orientates employees of the economic security service to block most of the management decisions associated } \\
\text { with risk, which negatively affects the speed of management decisions and the results of the enterprise. }\end{array}$ \\
\hline $\begin{array}{l}\text { 3. Based on an assessment of the speed of } \\
\text { enterprise response to changes in the } \\
\text { external environment }\end{array}$ & $\begin{array}{l}\text { 1. It does not take into account the effect of measures aimed at increasing security against internal threats } \\
\text { 2. It orientates employees of the economic security service to reduce the time taken for making managerial decisions } \\
\text { to the detriment of their validity. }\end{array}$ \\
\hline
\end{tabular}

\section{ASSESSMENT METHODOLOGY}

EESMS efficiency and effectiveness assessment should be carried out by enterprise management in order to monitor the achievement of the goals and objectives of EESMS functioning and to determine the directions of necessary changes.

The methodology for evaluating the effectiveness and efficiency of EESMS is based on a number of principles:

- comprehensiveness - taking into account the final and immediate results of the functioning of EESMS;

- taking into account the stage of development of EESMS;

- objectivity - the exclusion of subjective factors affecting the results of the assessment;

- profitability - the cost of resources for the assessment should be less than the effect obtained;
- digitalization - the use of procedures and information technology for the collection and processing of data in the evaluation process.

In developing the approach to assessing the effectiveness and efficiency of EESMS, we used the Balanced Scorecard concept [15]. This concept provides for the specification of the strategic goals of the enterprise using key performance indicator (KPI), including financial and non-financial indicators; planning KPI targets and ways to achieve them; monitoring and multi-criteria assessment of the activities of organizations based on KPI.

Advantages of using the Balanced Scorecard concept in developing a methodology for evaluating the effectiveness and efficiency of EESMS are the following:

- it ensures the unity of the assessment methodology in enterprises that have introduced the Balanced Scorecard; 
- it justifies the need to use financial and non-financial indicators;

- it allows comparing results of the assessment with the staff motivation system;

- it provides a balance between lagging and leading indicators.

Delayed indicators reflect the final results of EESMS functioning obtained as a result of actions over the past period.

The end result of EESMS functioning is to ensure the security of the economic interests and economic potential of a given business entity from external and internal threats in the short and long term.

Achieving the final result requires the implementation of a set of processes for the development, adoption and implementation of managerial decisions having various durations and planned implementation dates. In order to predict the final result and identify potential risks of failure to achieve goals in the long term, it is necessary to evaluate the immediate results of EESM functioning - the results of processes aimed at achieving the target level of economic security of the enterprise. Leading indicators are used to evaluate the immediate result.

Stages of developing a methodology for evaluating the effectiveness and efficiency of EESMS:

1) determination of the scope and principles of EESMS assessment;

2) substantiation of indicators' composition characterizing the effectiveness and efficiency of EESM and methods for their calculation;

3) development of an approach to the interpretation of the evaluation results;

4) substantiation of methods for assessing the degree of achievement of the final and immediate result of the functioning of EESMS.

EESMS performance assessment is based on the calculation of an integral indicator taking into account the degree of achievement of the target level of economic security of the enterprise and the level of implementation of plans for ensuring economic security. The assessment is carried out on the basis of comparison and analysis of actually achieved, forecasted and maximum permissible (critical) indicators' values.

Assessing the effectiveness of EESMS involves comparing the level of performance with the level of budget execution for the EESMS.

The proposed approach to assessing effectiveness is based on the assumption that the budget for the costs of EESMS operation is justified and allows you to fully fund the planned activities to ensure the economic security of the enterprise.

The information basis for evaluating the effectiveness and efficiency of EESMS is the following:
- strategic and operational plans of the enterprise, reports on the implementation of plans;

- threshold values of indicators of economic security of the enterprise;

- plans for ensuring the economic security of the enterprise and reports on their implementation;

- results of audits, results of forensic economic examinations and other reliable sources of information.

It is proposed to calculate the integral performance indicator of EESMS according to the formula:

$$
I E S=I E R \times a_{I E R}+I L \times a_{I L},
$$

where IES is the integral indicator of the effectiveness of EESMS, \%;

$I E R$ - the degree of achievement of the target level of economic security of the enterprise, \%;

$I L$ - level of implementation of plans for ensuring economic security, \%;

$a_{I E R}-$ weight coefficient of the degree of achievement of the target level of economic security of the enterprise;

$a_{I L}$ - weight coefficient of the level of implementation of EESMS economic security plans.

$$
a_{I E R}+a_{I L}=1
$$

When evaluating the performance of an EESMS in its infancy (the first three years of operation) $a_{I E R}=0.3, a_{I L}=0.7$.

When evaluating the effectiveness of EESMS, which is at the stage of maturity (functioning for more than three years) $a_{I E R}=0.7, a_{I L}=0.3$.

The rating scale for the actually achieved values of the integrated performance indicator has the following characteristics (table 2).

TABLE II. EESMS INTEGRATED PERFORMANCE INDICATOR RATING SCALE

\begin{tabular}{|l|l|l|}
\hline Option & $\begin{array}{c}\text { Positioning the actual value of the } \\
\text { indicator }\end{array}$ & Performance assessment \\
\hline 1 & $I E S \geq 90 \%$ & High performance \\
\hline 2 & $75 \% \leq I E S<90 \%$ & Partial performance \\
\hline 3 & $50 \% \leq I E S<75 \%$ & Low performance \\
\hline 4 & $I E S<50 \%$ & Extremely low performance \\
\hline
\end{tabular}

EESMS effectiveness assessment is based on the formula

$$
I E=\frac{I E S}{I C} \times 100,
$$

where $I E$ is the level of effectiveness of EESMS, \%;

$I C$ - the level of budget execution for the functioning of EESMS, \%.

- data of internal management accounting; 
The rating scale for the actually achieved EESMS performance level has the following characteristics (table 3).

TABLE III. EESMS PERFORMANCE LEVEL SCALE

\begin{tabular}{|l|l|l|}
\hline Option & \multicolumn{1}{|c|}{$\begin{array}{c}\text { Positioning the actual value of the } \\
\text { indicator }\end{array}$} & \multicolumn{1}{|c|}{$\begin{array}{c}\text { Performance } \\
\text { assessment }\end{array}$} \\
\hline 1 & $I E \geq 100 \%$ & High efficiency \\
\hline 2 & $75 \% \leq I E<100 \%$ & Average efficiency \\
\hline 3 & $I E<75 \%$ & Low efficiency \\
\hline
\end{tabular}

The degree of achievement of the target level of economic security of the enterprise is calculated by the formula:

$$
I E R=\sum_{\mathrm{n}=1}^{\mathrm{N}}\left(E R_{n} \times \frac{k_{n}}{100}\right)
$$

here $E R_{n}$ is the degree of achievement of the target value of the $\mathrm{n}$-th indicator of economic security of the enterprise, \%;

$N$ is the number of indicators used to assess the level of economic security of the enterprise;

$k_{n}$ - point assessment of the significance of the $\mathrm{n}$-th indicator of economic security of the enterprise, point.

$$
\sum_{n=1}^{N} k_{n}=100
$$

The degree of achievement of the target value of $n$-th indicator of economic security of the enterprise is proposed to be calculated by the formula:

$$
\mathrm{ER}_{\mathrm{n}}=\left\{\begin{array}{l}
\frac{X a_{n}-X c_{n}}{X t_{n}-X c_{n}} \times 100, \text { if } \frac{X a_{n}-X c_{n}}{X t_{n}-X c_{n}} \times 100 \leq 100 \\
100, \text { if } \frac{X a_{n}-X c_{n}}{X t_{n}-X c_{n}} \times 100>100
\end{array}\right.
$$

$X a_{n}$ - the actual value of the $n$-th indicator of economic security of the enterprise;

$X c_{n}$ - threshold value of the $n$-th indicator of economic security of the enterprise;

$X t_{n}$ - target value of the $n$-th indicator of economic security of the enterprise.

The composition of indicators used to assess the level of economic security of an enterprise should be formed taking into account the specifics of a particular enterprise and must include both financial (for example, the value of net assets, liquidity level, security ratio with own working capital, profitability of production), and non-financial indicators. In the composition of non-financial indicators, it is advisable to include indicators characterizing the position of the enterprise on the market, parameters of business processes, personnel development and innovative activity.

Target values of economic security indicators should be consistent with the strategic and operational plans of the enterprise. Threshold values are set as a result of multivariate forecasting of the long-term development of the enterprise, taking into account the analysis of the interests of its owners and other stakeholders.

The level of implementation of economic security plans is proposed to be calculated by the formula:

$$
I L=\sum_{\mathrm{m}=1}^{\mathrm{M}}\left(L_{m} \times \frac{w_{m}}{100}\right)
$$

$L_{m}-$ level of achievement of the planned value of the m-th indicator of direct results of ensuring economic security, \%;

$M$ - the number of indicators of direct results of ensuring economic security;

$w_{m}$ - point assessment of the significance of the m-th indicator of the direct result of ensuring economic security, point.

$$
\sum_{m=1}^{M} w_{m}=100
$$

The level of achievement of the planned value of the m-th indicator of direct results of ensuring economic security is calculated by the formula:

$$
\mathrm{L}_{\mathrm{m}}=\left\{\begin{array}{l}
\frac{O a_{m}}{O p_{m}} \times 100, \text { if } \frac{O a_{m}}{O p_{m}} \times 100 \leq 100 \\
100, \text { if } \frac{O a_{m}}{O p_{m}} \times 100>100
\end{array}\right.
$$

$O a_{m}$ - the actual value of the m-th indicator of the direct result of ensuring economic security;

$O p_{m}$ - the planned value of the m-indicator of the direct result of ensuring economic security.

The following indicators can be used as indicators of the immediate results of ensuring economic security: reduction in the amount of damage caused to the enterprise by suppliers, employees; the proportion of suppliers for which the dossier is formed; reduction in the proportion of overdue receivables; specific weight of the compensated damage from the actually caused damage; reduction of the amount of fines for violation of tax, antitrust, labor laws; number of preventive measures taken; average duration of an administrative investigation; the number of scheduled inspections; the number of documents agreed by the economic security service in a timely manner; the number of employees trained in the field of economic security; the number of proposals developed to improve the economic security of the enterprise accepted for implementation.

A specific set of indicators of the direct results of ensuring economic security is set by the enterprise independently, depending on the priority of the goals that are set for EESMS.

\section{CONCLUSION}

EESM efficiency and effectiveness assessment is carried out in order to monitor the achievement of the goals and objectives of EESMS functioning and determine the directions 
of necessary changes. The expediency of assessing the degree of achievement of the target level of economic security of the enterprise, the level of implementation of plans for ensuring economic security and an integrated performance indicator is substantiated. When evaluating the effectiveness of the system, it is proposed to evaluate the ratio of the integrated performance indicator and the level of budget execution for the functioning of the EESMS.

In order to reduce the complexity of the assessment, it is necessary to form the module "EESMS assessment" in the structure of the corporate information system.

The end result of evaluating the effectiveness and efficiency is the formation of adequate measures aimed at identifying and eliminating the problems of functioning of the EESMS, reducing the negative impact of challenges and threats to the economic security of the enterprise, preventing or minimizing possible damage.

\section{References}

[1] O.V. Khoroshilova, N.V. Bokovaya, E.M. Timofeeva, N.A. Serebryakova, Fundamentals of ensuring the economic security of the enterprise. Collective monograph. Voronezh: Sci. Book, 2019, pp. 10-15.

[2] Y.A. Salikov, V.S. Mikhailiuk, "Methodological approach to the terminological analysis of the key concepts of economic security", Proc. of Voronezh State Univer. of Engineer. Technol., vol. 81, no. 2, pp. 387-392, 2019. Retrieved from: https://doi.org/10.20914/2310-1202 2019-2-387-392

[3] I.V. Starchenko, "Improving the economic security management system of an agricultural enterprise", World science: problems and innovations, pp. 210-213, October 2018 [24th Int. sci.-pract. Conf. World sci.: probl. and innovat., 364 p., 2018].

[4] V.V. Krasnova, Y.S. Davlianidze, "Management of economic security of the enterprise in conditions of unstable development", Bull. of Donetsk National Univer., Ser. B, Econ. and Law, vol. 2, pp. 52-58, 2017.
[5] A.V. Kanahina, I.A. Medvedev, "The System of Management of the Economic Security of an Enterprise", pp. 212-215, April 2019, Actual Issues of the Development of Modern Society [9th Int. Sci. and Pract. Conf. Topical issues of the modern society development, 484 p., 2019].

[6] ISO 9000:Quality management systems. Fundamentals and vocabulary, 2015.

[7] N.A. Serebryakova, L.A. Nevzorova, "Methodological approaches to assessing the effectiveness of the enterprise's economic security management system. Socio-economic support for the development of business entities", Proc. of the Plekhanov Russ. Univer. of Econ., Voronezh Branch, vol. 8, pp. 128-132, 2017.

[8] R.A. Moshkova, "Criteria of the economic security management system of a railway enterprise", Econ.: yesterday, today, tomorrow, vol. 6, pp. 68-83, 2016.

[9] I.V. Starchenko, "Improving the economic security management system of an agricultural enterprise", pp. 210-213, October 2018 [24th Int. sci.pract. Conf. World science: problems and innovations, 364 p., 2018].

[10] J.A. Shadrina, G.A. Kochyan, M.A. Tleptserukov, "Criteria for the effectiveness of the functioning of the enterprise economic security management system in the context of sanctions on the economy", vol. 3, pp. 98-103, October 2016 [Int. sci.-pract. Conf. of the Strategy for the sustainable development of modern society: economic, social, philosophical, political, legal, trends and patterns, 136 p., 2016].

[11] L.N. Shentseva, N.A. Serebryakova, E.S. Dedova, D.Y. Treschevsky, T.A.Volkova, S.A. Volkova, O.A. Kavyrshina, I.V. Logunova, O.V. Khoroshilova, Fundamentals of Economic Security Management at the Macro and Micro Level. Voronezh: Sci. Book, 2018, pp. 150-155.

[12] V.Y. Padalkin, G.N. Strukov, A.M. Prygunkov, L.I. Churikov, "The impact of tax planning on the level of economic security of the company", Proc. of the Voronezh State Univer. of Engineer. Technol., vol. 81, no. 2, pp. 383-386, 2019.

[13] N.A. Serebryakova, S.A. Volkova, T.A. Volkova, S.V. Semenenko, "Methodological approaches to evaluation of economic security of enterprise", J. of Appl. Econ. Sci., vol. 11, no. 1, 2016.

[14] L.S. Budovich, "Security audit of an enterprise as a method for assessing the effectiveness of managing a security system", Power, vol. 2, pp. 47-50, 2007.

[15] R.S. Kaplan, D.P. Norton, Balanced Scorecard. From strategy to action. Moscow: CJSC Olympus-Busin., 2003, 320 p. 